\title{
PerCursos
}

\section{A prática docente efetivada na perspectiva da experimentação e da interdisciplinaridade através da temática água e sua biodiversidade em aulas para o Ensino Fundamental}

\begin{abstract}
Resumo
Este trabalho é resultante de elaboração e implementação de uma sequência de aulas, com perspectiva interdisciplinar, complementadas pelo desenvolvimento de atividades experimentais, norteadas pelas temáticas da água e biodiversidade aquática, como requisito do componente curricular Cotidiano da Escola - Grupo de Estudos Orientados (GEO) e das atividades de Regência do Programa Residência Pedagógica, da Universidade Federal do Pampa (UNIPAMPA), campus Caçapava do Sul, RS. Nesse contexto, foram ministradas aulas e práticas junto a uma turma do $6^{\circ}$ Ano do Ensino Fundamental de uma escola da rede pública estadual. Objetivando contemplar a proposta, foram efetivadas vinte e quatro aulas; tais intervenções caracterizaram-se por um viés interdisciplinar coadunando-se a atividades de caráter experimental. A experiência docente desenvolvida no estágio encontrou na interdisciplinaridade uma metodologia capaz de abranger a temática da água conectando conteúdos de diferentes disciplinas, exigindo da licencianda buscar e planejar recursos didáticos criativos e adequados para a organização das atividades e para a formulação de situações de aprendizagem. Além disso, recorreu-se à ferramenta da experimentação com o propósito de reproduzir, em sala de aula, um ambiente de Ciência, no qual, se pretendeu uma aproximação com os conceitos relacionados à água e sua biodiversidade, assim como, percebeuse uma conscientização sobre a temática ambiental.
\end{abstract}

Palavras-chave: Ensino. Biodiversidade. Abordagem interdisciplinar do conhecimento na educação.
Naira de Fátima Lopes de Freitas

Graduanda em Ciências Exatas

pela Universidade Federal do

Pampa - Unipampa.

Brasil

nairalopesdefreitas@gmail.com

\section{Denise Rosa Medeiros}

Mestre em Ensino de Ciências pela Univ. Federal do Pampa Unipampa. Professora da rede Básica de Ensino do município de Caçapava do Sul-RS. Brasil

Idenisemedeiros03@gmail.com

\section{Mara Elisângela Jappe Goi}

Doutora em Educação pela Univ.

Federal do Rio Grande do Sul -

UFRGS. Professora da

Universidade Federal do Pampa -

Unipampa. Professora dos

programas de Pós-Graduação em Ensino de Ciências da Unipampa e do Programa em Educação em

Ciências da UFRGS.

Brasil

maragoi28@gmail.com

\footnotetext{
Para citar este artigo:

FREITAS, Naira de Fátima Lopes de; MEDEIROS, Denise Rosa; GOI, Mara Elisângela Jappe. A prática docente efetivada na perspectiva da experimentação e da interdisciplinaridade através da temática água e sua biodiversidade em aulas para o Ensino Fundamental. PerCursos, Florianópolis, v. 21, n.47, p. 250 - 276, set./dez. 2020.
}

DOI: $10.5965 / 1984724621472020250$

http://dx.doi.org/10.5965/1984724621472020250 


\title{
A teaching practice carried out from the perspective of experimentation and interdisciplinarity through the theme of water and biodiversity in elementary school classrooms
}

\begin{abstract}
This work is the result of the elaboration and implementation of a sequence of classes, with an interdisciplinary perspective, complemented by the development of experimental activities, guided by the themes of water and aquatic biodiversity, as a requirement of the daily curriculum component School Routine - Group of Oriented Studies (GEO) and the Conducting activities of the Pedagogical Residency Program, at the Federal University of Pampa (UNIPAMPA), campus Caçapava do Sul, RS. In this context, classes and practices were given to a class from the 6th year of elementary school at a state public school. Twenty-four classes were carried out; such interventions were characterized by an interdisciplinary bias consistent with experimental activities. The teaching experience developed in the internship found in interdisciplinarity a methodology capable of covering the theme of water, connecting contents from different disciplines, requiring the undergraduate student to seek and plan creative and adequate didactic resources to organize the activities and formulate the learning situations. In addition, the experimentation tool was used to reproduce, in the classroom, a science environment, in which it was intended an approximation with the concepts related to water and its biodiversity, as well as it was perceived awareness of environmental issues.
\end{abstract}

Keywords: Teaching. Biodiversity. Interdisciplinary approach to knowledge in education. 


\section{Introdução}

Entende-se que o processo de ensinar é complexo e encontra-se em construção. Para Pimenta (1999) os cursos de formação inicial podem aproximar-se da realidade das escolas, buscando perceber as contradições existentes na educação. Para isso a educação pode ser vista como prática social, merecendo destaque às pesquisas, enquanto orientadoras da reflexão dos licenciandos, colaborando na estruturação de suas identidades como professores.

Essa construção da identidade docente, de acordo com Tardif (2010, p. 54), está relacionada ao próprio exercício da docência e ao saber docente, este, concebido pelo autor como “"saber plural' formado de diversos saberes provenientes das instituições de formação, da formação profissional, dos currículos e da prática cotidiana."

A pedagogia, em sua pluralidade, não é somente vista como objeto de saber, ela constitui-se, ainda, em um exercício que mobiliza diversos saberes. Nessa perspectiva, entende-se que os saberes vinculados ao conhecimento e articulados à prática pedagógica são essenciais para a atividade docente.

A práxis, imersa no contexto docente, é concebida por Gómez e Sacristàn (2007), enquanto uma atitude de: aprender a aprender, perceber, interpretar, raciocinar, investigar e intervir na realidade, enfatizadas como capacidades operativas que somente são construídas, agindo, mediando, intervindo na realidade.

A imersão no âmbito da docência, através de uma proposta didática, centrada no tópico da água e sua biodiversidade, concretizada a partir da componente de estágio-GEO e das atividades de regência do programa de Residência Pedagógica, constitui-se na temática que perpassa as etapas, as quais, consubstanciam este artigo. Neste trabalho, coexistem as alternativas metodológicas da interdisciplinaridade e da experimentação, que se encontram organizadas, em uma perspectiva de interação, obtida no contexto da efetivação das intervenções desenhadas.

A interdisciplinaridade, aqui abordada, remete à descoberta de interdependência de diferentes domínios do conhecimento. De acordo com Fazenda (2006), a interdisciplinaridade em sua dimensão real, se manifesta somente por meio do diálogo 
verdadeiro e do encontro autêntico; educando e educador são sujeitos de uma mesma situação, e, a eles caberá, em conjunto, a decifração do mundo.

Segundo Freire (1997), para compreender a teoria é preciso experimentá-la. Neste sentido, infere-se que a realização de experimentos em Ciências, representa uma ferramenta que possibilita ao aluno estabelecer uma dinâmica indissociável entre os conceitos e as práticas.

A Base Nacional Comum Curricular (BRASIL, 2017, p. 9), entre suas competências definidas para o Ensino Fundamental aborda a importância de estimular a curiosidade intelectual e investir em uma abordagem própria das ciências, “[...] incluindo a investigação, a reflexão, a análise crítica, a imaginação e a criatividade, para investigar causas, elaborar e testar hipóteses, formular e resolver problemas e criar soluções (inclusive tecnológicas) com base nos conhecimentos das diferentes áreas". Nesse viés, buscou-se contemplar um estudo sobre a temática “água", sob uma perspectiva interdisciplinar, contemplando atividades investigativas que envolvessem áreas distintas.

Este trabalho tem como objetivo, através do processo de desenvolvimento de uma sequência de atividades experimentais, com viés interdisciplinar, oportunizar ao aluno o domínio de saberes e práticas, adquiridos por meio de conexões estabelecidas entre diferentes disciplinas e por intermédio da realização de experimentos.

\section{Estágio e Pesquisa}

Compreendido como campo de conhecimento, o estágio concretiza-se na interação dos cursos de formação com o campo social, no qual se desenvolvem as práticas educativas. Sob esse enfoque, de acordo com Pimenta e Lima (2005), o mesmo suplanta sua tradicional redução à atividade prática e experimental, configurando-se em atividade de pesquisa.

O estágio com pesquisa constitui-se em uma temática de relevância significativa ao processo formativo da docência (GHEDIN; OLIVEIRA; ALMEIDA, 2015; PIMENTA; LIMA, 
2005). Dessa forma, percebe-se a importância de fazer da pesquisa um meio de produção de conhecimento e intervenção na prática social.

A aproximação de professores com o seu campo de atuação profissional requer a elaboração de um trabalho de síntese entre teoria e prática educativa. Para tanto, é imprescindível um contexto que articule, intrinsecamente, esses dois espaços da formação. Esta integração é possibilitada por intermédio do eixo representado pelo conceito de pesquisa, enquanto instrumento epistemológico e metodológico do processo de construção do conhecimento do professor em formação (GHEDIN; OLIVEIRA; ALMEIDA, 2015).

No decorrer do processo de aprender sobre sua profissão, futuros professores optam pelo que consideram adequado, adaptando-se às conjunturas nas quais se encontram. Para isso, utilizam-se de suas experiências e dos saberes adquiridos. Essa perspectiva está ligada a uma concepção de professor que não valoriza sua formação intelectual e reduz-se a observar os professores em aula, imitando esses modelos, sem proceder a uma análise crítica fundamentada teoricamente e legitimada na realidade social em que o ensino se processa (PIMENTA; LIMA, 2005).

Ghedin, Oliveira e Almeida, (2015) enfatizam que o estágio, quando alicerçado sobre a reflexão da ação, valoriza a prática docente como fonte de pesquisa e de autonomia do professor, proporcionando-lhe a responsabilidade por seu desenvolvimento profissional. Na concepção dos autores, é possível apreender a formação docente vinculada a determinadas concepções de sociedade, determinados projetos culturais e projetos educativos, ou seja, sempre com uma intencionalidade.

Nesse sentido, a pesquisa no contexto de formação de professores, insere-se no espaço de articulação de múltiplas dimensões, que abarcam o processo representado por teoria e prática, tais como o viés político, técnico, ético e estético do futuro profissional. Da mesma forma, a relação teoria-prática pode ser efetivada pelo processo de pesquisa, quando este se desenvolve ao longo de toda a formação. Pimenta (1997) compreende a pesquisa no campo da formação docente como um princípio cognitivo de compreensão da realidade e constitutivo da profissão docente. 
Conforme Ghedin, Oliveira e Almeida (2015), o estágio decorrente da pesquisa, compreende o ofício da docência e dos processos de construção da identidade do professor. Atrelados ao desenvolvimento e valorização de seus saberes, enquanto sujeitos intelectuais, os quais produzem conhecimento e participam de decisões dos sistemas educativos, encontrando-se intrínseco ao seu modo de constituir-se sujeito do processo de formação da própria humanidade.

A inclusão da pesquisa no processo de formação é um princípio que vem sendo defendido por muitos autores (ANDRÉ, 2001; LEITE; GHEDIN; OLIVEIRA; ALMEIDA, 2015; LÜDKE, 2010;). Ghedin, Oliveira e Almeida (2015), a entendem como um princípio educativo e cognitivo que orienta a uma nova percepção e visão sobre o professor, em uma perspectiva na qual, à medida que o compreendemos e formamos como sujeito do conhecimento, percebemos que, além de produzir seu próprio conhecimento, torna-se, também, construtor de seu modo de ser e de fazer-se, autonomamente, conforme elabora seus saberes.

Sob essa ótica, o professor, inserido no espaço da escola, durante sua formação, torna-se o sujeito que se compromete eticamente com os processos formativo e educativo, deixando de ser aquele profissional que apenas reproduz informações, e sim, as engendra continuamente, aprendendo a captar, a elaborar, a reunir as informações e transformá-las em conhecimento.

A mediação entre pesquisa educacional e a ação reflexiva docente constituem, conforme Pimenta (1999), a base de uma nova epistemologia da prática, pois, somente alicerçando-se sobre essa premissa, o saber docente, enquanto elaboração teórica, se constitui.

Para Ghedin, Oliveira e Almeida (2015), as pesquisas devem ser compreendidas como um elemento-chave na produção das ciências, na construção do conhecimento humano, na elaboração de técnicas e na formação de profissionais. Enfatizando que, sendo a pesquisa eficaz no processo formativo de qualquer profissional, mais propícia, ainda, se mostrará na formação dos professores, já que, estes serão responsáveis por formar os demais profissionais. Para tanto, o processo formativo docente, concatenado a 
uma formação de pesquisa, constitui-se recurso fundamental ao processo de construção da identidade docente.

\section{A Interdisciplinaridade como uma intencionalidade que relaciona diversos}

\section{saberes}

A interdisciplinaridade pode ser compreendida como um processo metodológico que oportuniza ao docente, trabalhar em sala de aula, buscando a construção do conhecimento do aluno em relação a um contexto, no qual, se propõe um tema com abordagens em diferentes disciplinas. Em uma perspectiva voltada a compreender as conexões entre as diversas áreas do saber, unindo-se para ultrapassar o conhecimento fragmentado. Para Fourez (2002), a interdisciplinaridade configura-se como condição primeira da descompartimentação das práticas pedagógicas no ensino.

A importância da interdisciplinaridade na produção do conhecimento e de competências vem sendo considerada por diversos autores, colocando-a em evidência no âmbito da educação e, de forma mais específica, no plano da formação docente (LENOIR, 2005). O autor entende que existem diferentes leituras sobre a temática, decorrentes do fato que os atores sociais, pesquisadores, formadores universitários ou especialistas integram culturas que alicerçam essas diferenças conceituais.

De acordo com Fourez (2002), o paradigma da interdisciplinaridade apoia-se no pressuposto de que certas situações não podem ser dominadas no âmbito de um paradigma disciplinar particular, e, requerem a articulação de diferentes contribuições disciplinares.

Ao tratar da importância em proporcionar uma integração entre as disciplinas, Fazenda explicita que:

Eliminar as barreiras entre as disciplinas é um gesto de ousadia, uma tentativa de romper com um ensino transmissivo e morto [...]. Nas diferentes disciplinas há sempre mais de uma possibilidade metodológica de organização das aulas. A interdisciplinaridade oferece algumas 
reflexões, fruto das pesquisas realizadas no interior de escolas públicas e privadas, que permitem a eleição de um outro olhar sobre a transposição das barreiras que tendem a se levantar diante da tênue linha que caracteriza a especificidade de uma disciplina. (FAZENDA, 2006, p. 87-88)

Para Lenoir (2005, p. 3), atualmente, em razão do fenômeno da mundialização, a noção de interdisciplinaridade conhece um verdadeiro êxito histórico. A mudança radical da organização da sociedade, através da “[...] substituição de Estados-Nação, por um sistema de grandes corporações internacionais e das culturas nacionais por um compromisso sem alma, exerce efeitos importantes diretos sobre o sistema de educação escolar". Cabe aqui, enfatizar a importância em desenvolver um olhar plural dos docentes acerca das interculturalidades da sociedade, que remetem a uma complexidade imbricada ao tema do ensino e da aprendizagem, a qual deve ser considerada no atual momento da educação e requer uma intencionalidade para romper com um processo de ensino engessado.

É possível perceber a interdisciplinaridade como um elo entre o entendimento das disciplinas nas suas mais variadas áreas, que em uma postura inovadora e dinâmica, abarca uma maior dimensão da aprendizagem ao buscar a superação do conhecimento fragmentado, o qual, já não atende as complexas questões contemporâneas.

Em um contexto de profundas transformações, manifestou-se uma questão social, que foi além do simples questionamento da organização dos estudos. Assim, para abordar a problemática do sentido do ser humano no mundo e para integrar os saberes disciplinares, dispõem-se em torno de um processo de percepção de uma realidade em transformação e de resolução de problemas contemporâneos, estes marcados por sua destacada complexidade (LENOIR, 2005).

Para Thiesen (2008), a presença do enfoque interdisciplinar na educação constitui um dos pressupostos diretamente relacionados a um contexto mais amplo e complexo de mudanças, que abrange, não somente, a área da educação, mas também, outros setores da vida social, como a economia, a política e a tecnologia. Para o autor, trata-se de uma grande mudança paradigmática que se encontra em curso. 
A questão da interdisciplinaridade na formação dos professores, Fourez (2002), apresenta duas ordens diferentes, porém complementares: uma ordem científica que abarcaria a construção dos saberes interdisciplinares, na qual, a organização dos mesmos, concebida como o alicerce do conhecimento científico no decorrer da formação docente, estruturaria a hierarquia de disciplinas, sua dinâmica, as interações que as compõem, sua mobilidade de conceitos e a comunicação dos saberes na sequência a serem sistematizados. Essa premissa direcionaria "[...] à busca da cientificidade disciplinar e com ela o surgimento de novas motivações epistemológicas e novas fronteiras existenciais" (FAZENDA, 2008, p. 18).

Já a segunda ordem, de acordo com Fourez (2002), contemplaria a premissa social; esta perscrutaria o desdobramento dos saberes científicos interdisciplinares ao contexto social, político e econômico. Nesse sentido, Fazenda (2008) entende que essa perspectiva social revela o propósito em alcançar toda a complexidade do real e a importância de considerar as interações que o constituem.

Ao analisar a interdisciplinaridade, Frigotto (1995, p. 26) explicita que ela se impõe pela forma do "homem produzir-se enquanto ser social e enquanto sujeito e objeto do conhecimento social”. Ela alicerça-se no caráter dialético da realidade social, que pode ser uma e diversa ao mesmo tempo, de modo que, nos impõe delimitar os objetos de estudo, sem, no entanto, fragmentá-los. Essa proposição implica que, mesmo delimitando o problema a ser estudado, as múltiplas determinações e mediações históricas que o constituem, não podem ser abandonadas (THIESEN, 2008).

Desse modo, infere-se que a interdisciplinaridade foi solicitada não somente, por forças científicas ligadas a obstáculos socioeconômicos, mas, especialmente, por forças ligadas à complexidade da realidade social e às exigências da técnica e das atividades sociais cotidianas (LENOIR, 2005). Nesse viés, segundo o autor, faz-se necessário recorrer a interdisciplinaridade em razão da exigência de um outro método de análise de nosso mundo, assim como, em função de propósitos sociais, em uma conjuntura, na qual cada uma das disciplinas científicas não consegue, sozinha, responder apropriadamente às problemáticas altamente complexas. 
Segundo os Parâmetros Curriculares Nacionais (BRASIL, 1998), na perspectiva escolar, a interdisciplinaridade não pretende criar disciplinas ou saberes, mas utilizar o conhecimento de várias disciplinas para resolver um problema ou compreender um determinado tópico sob diferentes pontos de vista. Sob essa perspectiva, o professor precisa tornar-se um profissional com visão integrada da realidade, apropriando-se das múltiplas relações conceituais que sua área de formação estabelece com as outras áreas.

O conhecimento não deixará de ter seu caráter de especialidade, principalmente, quando profundo, sistemático, analítico e meticulosamente construído. Porém, ao educador caberá o papel de reconstrui-lo dialeticamente na relação com seus alunos, por meio de métodos e processos verdadeiramente produtivos (THIESEN, 2008).

No ensino, a interdisciplinaridade não pode ser "uma junção de conteúdos, nem uma junção de métodos, muito menos, a junção de disciplinas". Ela requer um novo modo de pensar e de agir em uma postura que privilegie a abertura para uma vivência interativa, mediada por conhecimentos diversificados, buscando-se novas formas de interlocução, interpretação e ação que integrem os conhecimentos das ciências (FAZENDA, 1993, p. 64).

$\mathrm{Na}$ concepção de Japiassu (2011), a interdisciplinaridade se caracteriza pela intensidade das trocas entre os especialistas e pelo grau de integração real das disciplinas. Lück a define como:

[...] o processo que envolve a integração e engajamento de educadores, num trabalho conjunto, de interação das disciplinas do currículo escolar entre si e com a realidade, de modo a superar a fragmentação do ensino, objetivando a formação integral dos alunos [...]. (LÜCK, 1994, p.64)

Fazenda (1979) pontua que a inserção da interdisciplinaridade requer, de forma simultânea, uma transformação profunda da pedagogia, um novo tipo de formação de professores, um novo jeito de ensinar, e complementa: 
Passa-se de uma relação pedagógica baseada na transmissão do saber de uma disciplina ou matéria, que se estabelece segundo um modelo hierárquico linear, a uma relação pedagógica dialógica na qual a posição de um é a posição de todos. Nesses termos, o professor passa a ser o atuante, o crítico, o animador por excelência. (FAZENDA, 1979, p. 48-49)

No universo da escola, ou mesmo no cotidiano de sala de aula, são múltiplas as relações que se estabelecem e interferem no desenvolvimento e organização das atividades docentes, caracterizando um cenário complexo que abarca os processos formadores do trabalho escolar. Para Morin (2015), uma realidade complexa requer um pensamento, também complexo, oportunizando a reelaboração do pensamento, direcionando-o à contextualização, a articulação e à interdisciplinaridade dos conhecimentos produzidos pela humanidade.

De acordo com Fazenda (2006), ao tratarmos da interdisciplinaridade há uma relação de reciprocidade, de interação que pode ajudar no diálogo entre diferentes conteúdos, de modo que, integrar conhecimentos significa aprender, disseminar e transformá-los. Para a autora, a interdisciplinaridade surgiu como uma nova pedagogia capaz de identificar o vivido e o estudado, construindo conhecimento a partir da relação de múltiplas e diversas experiências.

No campo educacional, a interdisciplinaridade emerge no contexto da dialogicidade e da integração das ciências e do conhecimento, na perspectiva de romper com o caráter de segmentação dos saberes. Esse olhar sinérgico entre disciplinas, poderá tornar possível uma leitura, ao mesmo tempo, abrangente e específica, na construção dos saberes, habilidades e competências.

\section{Saberes profissionais na perspectiva de Tardif}

Tardif (2002) confere à noção de "saber" um sentido amplo que abarca os conhecimentos, as competências, as habilidades (ou aptidões) e atitudes dos docentes, ou seja, ao que foi denominado de saber, de saber-fazer e de saber-ser. Assim, os saberes docentes não podem estar dissociados de outras dimensões do ensino, nem do trabalho 
específico, realizado cotidianamente, pelos professores, uma vez que, no âmbito profissional, não é admissível falar de seus saberes, sem interligá-los aos condicionantes e ao contexto do seu trabalho (TARDIF, 2002).

Nesse sentido, tais saberes encontram-se conectados à identidade dos professores, sua experiência de vida, sua história profissional, integrando suas relações com os alunos em sala de aula e com os demais atores escolares. Sob esse viés, o saber profissional docente situa-se na confluência de vários saberes oriundos da sociedade, da instituição escolar, dos outros sujeitos educacionais, das universidades (TARDIF, 2002).

A relação dos professores com os saberes, segundo Tardif (2002), não pode ser reduzida à simples transmissão de conhecimentos já construídos, uma vez que sua prática integra diversos saberes, com os quais os profissionais mantêm diferentes relações. Nessa perspectiva, o autor define o saber docente, como plural, formado pela combinação de saberes oriundos da formação profissional e de saberes disciplinares, curriculares e experienciais.

Os saberes profissionais, para o autor, são aqueles trabalhados pelas instituições de formação de professores, onde articulam-se as ciências da educação e os saberes pedagógicos. Já os saberes disciplinares são aqueles que correspondem aos diversos campos do conhecimento, aos saberes de que dispõe a nossa sociedade, tais como encontram-se hoje, integrados nas universidades sob a forma de disciplinas. Os saberes curriculares apresentam-se, concretamente, sob a forma de programas escolares que os professores devem aplicar. Finalmente, os saberes experienciais são aqueles desenvolvidos no exercício de suas funções e de suas práticas, fundamentam-se em seu trabalho cotidiano, emergem da experiência e são por ela validados, reportam-se ao seu saber-fazer e saber-ser (TARDIF, 2002).

Mesmo afirmando e desenvolvendo sua argumentação no sentido de que há diversos saberes relacionados ao fazer dos professores, Tardif (2002) enfatiza os saberes experienciais em relação aos demais saberes docentes. Essa posição de destaque se apoia, principalmente, na relação de exterioridade, mantida pelos professores, quanto aos saberes curriculares, disciplinares e da formação pedagógica, e acarreta a valorização 
dos seus saberes experienciais, considerando que é sobre eles que os professores mantêm o controle, tanto no que concerne a sua produção, quanto a sua legitimação (TARDIF, 2002).

Dessa forma, é possível inferir, tendo como base as concepções de Tardif (2002), que as múltiplas articulações que envolvem a prática dos professores e seus saberes, delineiam a docência como um grupo profissional que deverá ser capaz de dominar, integrar e mobilizar tais saberes enquanto conjuntura necessária à sua prática. Assim, o professor deverá conhecer sua disciplina e seu programa, além de possuir certos conhecimentos relativos às ciências da educação e à pedagogia, desenvolvendo um saber prático alicerçado em sua experiência cotidiana com seus alunos (TARDIF, 2002).

Os professores produzem saberes específicos ao seu ofício e deliberam sobre suas próprias práticas, partilhando-as, aperfeiçoando-as, inserindo a estas, inovações que possibilitam aumentar sua eficiência. Desse modo, a prática profissional não é concebida como um simples campo de aplicação de teorias produzidas, exteriormente a ela. Sob essa ótica, a mesma converte-se em "[...] um espaço original relativamente autônomo de aprendizagem e de formação para os futuros práticos, bem como um espaço de produção de saberes e de práticas inovadoras pelos professores experientes" (TARDIF, 2002, p. 286).

Para Tardif (2010, p. 31), “Um professor é antes de tudo alguém que sabe alguma coisa e cuja função consiste em transmitir esse saber aos outros". Nessa perspectiva, o professor desenvolve um saber prático no cotidiano com os alunos, mediado por outros saberes pedagógicos que irão orientar suas ações na construção do conhecimento que possui.

Assim, na perspectiva dos professores, enquanto atores competentes e sujeitos ativos, Tardif (2002) propõe que as relações entre teoria e prática devem ser repensadas, de forma que, sua prática seja concebida como um espaço de produção de saberes específicos, derivados da mesma, e, não somente, um espaço de aplicação de saberes provenientes da teoria. Nesse sentido, é possível apreender o professor como portador 
do conhecimento, alguém que desenvolve e possui teorias, aprendizados e saberes decorrentes de sua própria prática ou ação.

\section{Metodologia}

O presente trabalho, de cunho qualitativo, foi desenvolvido no componente GEO Grupo de Estudos Orientados, com a elaboração e concretização de 24 aulas, junto a uma turma de $6^{\circ}$ Ano, do Ensino Fundamental, com escopo voltado aos temas água e biodiversidade aquática, conforme o Quadro 01, explicitado nesta seção.

Foram realizadas, como exigência da componente curricular, intervenções desenvolvidas sob um enfoque interdisciplinar, abarcando: Ciências, Geografia, Matemática. Tendo a água como tema norteador, foram elaboradas aulas que abordaram desde o percentual de água nos órgãos vitais do corpo humano até os índices que mostram a distribuição de água no planeta Terra, entre outras.

O planejamento integra, ainda, a implementação de uma sequência de atividades experimentais, voltadas ao estudo da biodiversidade aquática, com utilização de microscópios e lupas, além de investigação, análise e descrição de amostras de água misturada a diferentes elementos.

A água utilizada na aula prática foi colhida pela estagiária, em um lago localizado próximo à UNIPAMPA. Os equipamentos (microscópios e lupas) foram cedidos por esta instituição, em razão da escola onde foi desenvolvido o estágio não dispor dos mesmos. A turma na qual as aulas foram realizadas, era constituída por 27 alunos matriculados, com idades entre 11 e 14 anos, em uma escola da rede pública do Rio Grande do Sul.

A temática água, tem sua relevância no Ensino das Ciências da Natureza, pois apresenta-se como substância vital à sobrevivência das espécies, à continuidade do planeta e, consequentemente, à humanidade. Embora o volume de água na Terra seja imenso, cerca de $97 \%$ da água do planeta é salgada, sendo apenas 3\% com potabilidade para consumo, o que a torna um recurso merecedor de cuidados e preocupação.

Segundo Grassi: 
Nosso planeta está inundado d'água; um volume aproximado de 1,4 bilhão de $\mathrm{km}^{3}$ cobre cerca de $71 \%$ da superfície da Terra. Apesar disso, muitas localidades ainda não têm acesso a quantidades de água com características de potabilidade adequadas às necessidades do consumo humano. (GRASSI, 2001, p.31).

A Base Nacional Comum Curricular (BRASIL, 2017) enfatiza a importância de uma abordagem inter-relacionada de suas três Unidades Temáticas, no desenvolvimento de temas como sustentabilidade socioambiental, o ambiente, saúde e tecnologia. Nessa perspectiva, é importante que os estudantes percebam a água como um recurso raro e imprescindível à saúde e ao meio ambiente. O documento destaca, ainda, que seja proporcionado ao aluno o entendimento do papel substancial da biodiversidade para a manutenção dos ecossistemas e do equilíbrio socioambiental. Capacitando-os a avaliar hábitos de consumo que envolvem recursos naturais.

O projeto de implementação da sequência de atividades experimentais, cujo desenvolvimento utilizou diferentes misturas de água doce, acondicionadas em garrafinhas pet, além de observação e análise das amostras, por meio de lupas e microscópios, com o objetivo de estudar a biodiversidade da água, foi realizado com a turma de $6^{\circ}$ Ano, como atividade de pesquisa integrante do Trabalho de Conclusão de Curso da estagiária. Fato, este, que resultou na inclusão desta sequência de práticas à proposta de aulas construída no âmbito da componente Cotidiano da Escola-GEO, que passou a integrar o projeto de pesquisa, tendo em vista que o tópico "água" constitui-se objeto de análise, coadunando-se ao tema das aulas a serem ministradas, com viés interdisciplinar, no estágio e no Programa Residência Pedagógica.

O desenvolvimento do projeto apresentou em sua primeira etapa a aplicação de um questionário com perguntas (nove questões abertas e uma fechada), norteadas pelos tópicos água e biodiversidade aquática, que se constituíram em objeto de estudo. A atividade investigativa denominada Detetives da Água, representou a segunda etapa da proposta. Em um momento seguinte, desenvolveram-se as práticas com a utilização de lupas e microscópios. Essas intervenções foram complementadas por um instrumento 
impresso, com questionamentos e solicitação de descrições e desenhos, a ser respondido individualmente, pelos alunos. As atividades encerram-se com a produção de relato, no qual os estudantes descreviam suas percepções.

As aulas elaboradas e implementadas com enfoque interdisciplinar buscaram estabelecer relações conceituais que envolvessem outras disciplinas, além das Ciências Naturais. Neste trabalho foi desenvolvida uma integração entre as disciplinas de Geografia, Matemática e Ciências, tendo a Água como temática.

As intervenções tiveram, incialmente, uma introdução caracterizada por uma aula expositivo-dialogada, na qual eram abordados conceitos e realizados estudos sobre textos que tratavam dos conteúdos relacionados à temática. Após, eram realizadas aulas fazendo uso de ferramentas como gráficos, mapas, gravuras, imagens, como também, as atividades investigativas e experimentais.

A interdisciplinaridade, como forma de encontrar conexões entre as disciplinas ao estudar um tema, dialoga com as competências estabelecidas pela BNCC (BRASIL, 2017), quando busca entender a realidade, investigar, levantar hipóteses, contextualizando a aprendizagem à vivência dos estudantes. Neste trabalho, a água revelou-se um recurso capaz de produzir alternativas com múltiplas possibilidades investigativas, constituindose um tema instigante a ser trabalhado em diferentes disciplinas, além de oportunizar um vínculo entre os conhecimentos trabalhados e situações do cotidiano dos alunos.

Os dados, disponibilizados pelas intervenções realizadas, eram registrados por meio de exercícios e atividades fornecidos em material impresso, a serem respondidos pelos estudantes, para posterior análise e avaliação. Esta, também realizada no decorrer das atividades, com base na participação e interação dos alunos. Recorreu-se, ainda, ao Diário de Bordo, como forma de registro das atividades desenvolvidas, tendo o material, apontado no mesmo, sido utilizado como fonte de análise e orientação para o presente trabalho. 
Quadro 01 - Atividades implementadas

\begin{tabular}{|c|c|c|}
\hline $\begin{array}{l}N^{\circ} \text { de Aulas } \\
(50 \text { min cada aula) }\end{array}$ & Conteúdo & Desenvolvimento da atividade \\
\hline o1 Aula & $\begin{array}{l}\text { Abordando a água (de } \\
\text { modo geral, tanto água } \\
\text { doce como água salgada) e } \\
\text { sua biodiversidade. }\end{array}$ & $\begin{array}{l}\text { Questionário impresso (com } 10 \\
\text { questões, sendo o9 abertas e } 01 \\
\text { fechada) a ser respondido pelos } \\
\text { estudantes. }\end{array}$ \\
\hline 02 Aulas & $\begin{array}{l}\text { A água (doce) e sua } \\
\text { biodiversidade. }\end{array}$ & $\begin{array}{l}\text { Atividade Experimental com amostra } \\
\text { de água colhida de um lago. }\end{array}$ \\
\hline 01 Aula & A água e os Seres vivos. & Aula expositivo-dialogada. \\
\hline 02 Aulas & A água e os seres vivos. & Realização de exercícios \\
\hline 03 Aulas & $\begin{array}{l}\text { A Biodiversidade existente } \\
\text { na água. }\end{array}$ & $\begin{array}{l}\text { Atividades experimentais utilizando } \\
\text { lupas e microscópios }\end{array}$ \\
\hline 02 Aulas & $\begin{array}{l}\text { A Biodiversidade da água; } \\
\text { A água e a Saúde. }\end{array}$ & $\begin{array}{l}\text { Produção de texto relacionado às } \\
\text { atividades experimentais (tratando da } \\
\text { biodiversidade da água) realizadas em } \\
\text { aula anterior e, no segundo período, } \\
\text { atividade relacionada à água e saúde. }\end{array}$ \\
\hline 02 Aulas & $\begin{array}{l}\text { A importância da água para } \\
\text { os seres humanos; } \\
\text { A composição de água do } \\
\text { corpo humano. }\end{array}$ & $\begin{array}{l}\text { Atividade na qual foram abordados } \\
\text { tópicos relacionados aos percentuais } \\
\text { de água que formam o corpo humano. } \\
\text { Para tanto, foram apresentadas aos } \\
\text { estudantes noções de porcentagens e } \\
\text { gráficos. }\end{array}$ \\
\hline 01 aula & $\begin{array}{l}\text { Distribuição de água no } \\
\text { planeta Terra. }\end{array}$ & $\begin{array}{l}\text { Realizada introdução e após, atividades } \\
\text { com utilização de gráficos para melhor } \\
\text { compreensão da distribuição e } \\
\text { quantidades de água doce e água } \\
\text { salgada no planeta. }\end{array}$ \\
\hline 02 Aulas & A Hidrosfera. & $\begin{array}{l}\text { Disponibilizado texto impresso sobre o } \\
\text { tema da Hidrosfera. Na sequência, } \\
\text { foram realizados exercícios, também } \\
\text { impressos sobre o tema. }\end{array}$ \\
\hline 02 Aulas & $\begin{array}{l}\text { Água potável e Utilização } \\
\text { da água; } \\
\text { Ciclo da água. }\end{array}$ & $\begin{array}{l}\text { Introdução com texto tratando da } \\
\text { problemática que envolve a água } \\
\text { potável. } \\
\text { Atividade construindo o processo } \\
\text { representativo do ciclo da água, através } \\
\text { da elaboração de maxi-cartaz } \\
\text { (constituído de diversas peças gráficas) } \\
\text { que teve sua construção realizada } \\
\text { conjuntamente com os alunos. }\end{array}$ \\
\hline
\end{tabular}




\begin{tabular}{|l|l|l|}
\hline 01 Aula & Ciclo da água. & $\begin{array}{l}\text { Abordagem do conteúdo referente ao } \\
\text { ciclo da água, verificando e revisando } \\
\text { os conceitos trazidos e aprendidos em } \\
\text { aula anterior e aplicação de exercícios. }\end{array}$ \\
\hline O2 Aulas & A solubilidade da água. & $\begin{array}{l}\text { Atividade experimental, realizada no } \\
\text { laboratório de Ciências da escola. }\end{array}$ \\
\hline
\end{tabular}

Fonte: Elaborado pelos autores, 2020.

\section{Resultados}

A seguir, apresentam-se as análises dos momentos mais relevantes no percurso de concretização das atividades planejadas.

O questionário, aplicado incialmente, permitiu verificar algumas concepções dos alunos relacionadas à água e sua diversidade. Inteirar-se dos conhecimentos prévios dos estudantes poderá resultar em um suporte, por meio do qual é oportunizado trabalhar as informações pertinentes ao aprendizado e a apropriação dos novos conhecimentos. Nessa perspectiva, Moreira pontua que:

Novas ideias e informações podem ser aprendidas e retidas, na medida em que conceitos relevantes e inclusos estejam adequadamente claros e disponíveis na estrutura cognitiva do indivíduo e funcionem, dessa forma, como ponto de ancoragem às novas ideias e conceitos. (MOREIRA, (2003, p. 153)

A análise dessa primeira atividade revelou que a temática da água e dos organismos que nela habitam, possivelmente, necessite ser contemplado com maior atenção por educadores dos Anos Iniciais, uma vez que apresentou um elevado número de respostas descontextualizadas, simplistas ou conceitualmente incorretas. Em algumas respostas, os alunos chegaram a confundir organismos vivos e não vivos. Para Chassot (2000), é necessário que seja democratizado o acesso aos conhecimentos científicos, tendo em vista a formação dos estudantes, oportunizando-lhes, assim, uma aproximação à epistemologia e à linguagem própria da Ciência. Entende-se, dessa forma, que o indivíduo precisa estar em contato com essa nova linguagem para que, durante o 
processo de aprendizagem, possa desenvolver habilidades para ampliar sua leitura de mundo (CASTRO; MOTOKANE, 2017).

A atividade experimental realizada em aula denominou-se "Os detetives da Água". Nesta, eram disponibilizados aos estudantes, quatro conjuntos de garrafinhas pet, sendo, cada um deles, constituído por cinco garrafinhas, representadas pelas letras A, B, C, D, E, contendo amostras de água de açude, água da torneira, água com sal, água com detergente e água com terra, respectivamente, sem que os alunos soubessem o que havia em cada frasco.

Os estudantes, que representavam os detetives, deveriam observar, analisar e descrever suas percepções e posicionamentos sobre cada uma das amostras. Foi necessário deixar claro que as garrafinhas não poderiam ser abertas, e sim, analisadas, observando-as, com o propósito de chegar a hipóteses sobre os conteúdos das amostras. Para Sasseron e Carvalho (2011), é necessário desenvolver atividades que, em sala de aula, permitam as argumentações entre alunos e professores em diferentes momentos da investigação e do trabalho envolvido.

A atividade mostrou-se dinâmica, os alunos participativos, interagindo com os colegas e a pesquisadora. As garrafinhas que continham as amostras foram manuseadas, comparadas e investigadas pelos estudantes, que demonstraram, por meio de perguntas e suposições, interesse e curiosidade. Após, os estudantes responderam, individualmente, formulário impresso, onde registravam suas percepções e hipóteses sobre o conteúdo de cada garrafinha. A interação é ressaltada e considerada por Borges (2002), a palavra-chave, que representa o construtivismo; nela, os alunos poderão ser estimulados a participar das atividades experimentais, buscando respostas e soluções.

A Água e os Seres vivos formam as temáticas abordadas na aula seguinte. Nesta, foi tratada a concepção evolucionista, segundo a qual, os primeiros seres vivos surgiram na água. A importância da água para os seres vivos, incluindo os seres humanos, e as funções que esse elemento substancial exerce no corpo humano foi outro tópico retratado. 
A continuidade dessa temática foi desenvolvida em aula em que se buscou um viés interdisciplinar; o tema água foi abordado com os estudantes, investigando a quantidade de água que compõe os principais órgãos do corpo humano, sendo trazidas para as Ciências Naturais noções sobre o conteúdo de porcentagem, penetrando a área da Matemática. No decorrer dessa atividade, foi possível perceber como os alunos mostraram-se surpresos com a quantidade de água (representadas em figuras do copo humano, contendo os percentuais calculados para cada órgão), encontrada nos principais órgãos do corpo humano. De acordo com Gasparin:

A tarefa docente consiste em trabalhar o conteúdo científico e contrastá-lo com o cotidiano a fim de que os alunos [...] através das operações mentais de analisar, comparar, explicar, generalizar, etc., apropriem-se dos conceitos científicos e neles incorporem os anteriores, transformando-os também em científicos constituindo uma nova síntese mais elaborada. (GASPARIN, 2002, p. 58)

A intervenção interdisciplinar abordando tópicos de Ciências Naturais, Matemática e Geografia foi realizada em aula posterior, quando foi trabalhado o tema da distribuição de água doce e salgada no planeta, através de percentuais detalhados por meio de gráficos de pizza, representando o planeta Terra e suas quantidades de água. A distribuição da água doce no mundo e, principalmente, no Brasil foi o mote de algumas intervenções sequenciais, em que se abordou a abundância e irregularidade desse recurso, de acordo com cada região, além das hidrelétricas e os aquíferos, fazendo-se uso de mapa com a hidrografia do Brasil. Infere-se que essa abordagem, na qual em uma disciplina, os conteúdos referentes a um determinado tema permearam as fronteiras de outras, possibilitaram uma apropriação, por parte dos estudantes, dos novos conhecimentos apresentados. O Viés interdisciplinar vem sendo estudado por pesquisadores que o consideram como um potencial para acontecer os processos de ensino e de aprendizagem (BRASIL, 1998; FAZENDA, 1979, 2006, 2008; FRIGOTTO, 1995; JAPIASSU, 2011; LENOIR, 2005; LÜCK, 1994). 
Durante a aula na qual foi efetivada a sequência de atividades sobre a biodiversidade da água, disponibilizou-se, inicialmente, aos alunos, um texto impresso, intitulado: "Microrganismos também vivem na água", dividido em sete partes, destacadas com diferentes cores, que seriam distribuídas aos estudantes (organizados em grupos): cada grupo escolheria uma cor e deveria abordar o conteúdo pelo qual ficou responsável para leituras, discussões e elucidações de dúvidas que surgissem sobre os termos científicos ou desconhecidos. A aula teórica buscou uma técnica que fosse investigativa e exigisse a participação dos alunos. Para Casaca (2015), é essencial entender as concepções dos estudantes sobre a biodiversidade, condição indispensável para repensar o processo de ensino-aprendizagem. Para tanto, é necessário que haja uma disponibilidade de informações, realizada de forma consciente, e, não há melhor lugar para isso do que a escola. Nesse momento, é possível que o professor coloque em prática os seus saberes curriculares, apresentando aos alunos os conteúdos dos programas escolares e que devem aplicar e trabalhar (TARDIF, 2010).

Sequencialmente, desenvolveu-se atividade que envolvia elementos como - água retirada de um lago, lupas, placas de Petri, instrumento impresso, com um roteiro da prática e uma questão em que eram solicitados uma descrição da atividade, conjuntamente a um desenho, que a representasse. A água, colhida, anteriormente, pela licencianda, em um lago, era disponibilizada em um recipiente grande, onde era peneirada e, a amostra resultante, levada em uma placa de Petri, até a lupa para visualização. Após, os estudantes descreveram a atividade e desenharam o que observaram no instrumento impresso, que lhes foi entregue, individualmente.

A etapa seguinte consistiu na atividade com os microscópios. O processo de realização da atividade foi semelhante ao experimento com a lupa: os alunos colhiam a água com uma peneira e a levavam até o microscópio, onde eram visualizados os microrganismos e as macrófitas. Tendo sido fornecido, também, um instrumento impresso, este contendo, além do roteiro, indicando como seria desenvolvida a experimentação, uma série de questões abertas, a serem respondidas pelos alunos, tais como: "Quando você olha para essa amostra de água, você imagina que existe algo 'invisível', isto é, coisas que não conseguimos enxergar a olho nu?"; "Para verificar a 
presença ou não de microrganismos precisamos de, além de outros materiais, que equipamento?”; “O que você entende que sejam esses organismos visualizados no microscópio?". Também foi solicitada produção de desenho que retratasse o que haviam observado. A atividade prática para Bartzik e Zander (2016), é a interação entre alunos e materiais concretos, sejam objetos, instrumentos, microscópio e, por meio desse envolvimento, que se torna natural e social, estabelecem-se relações que abrirão possibilidades de apropriar-se de novos conhecimentos.

No decorrer das atividades com lupas e microscópios, a turma estava bastante entusiasmada querendo manipular a água do lago e os equipamentos. Muitos não conseguiam aguardar a sua vez para execução da atividade, ansiosos em proceder à investigação, através dos instrumentos disponibilizados. A aprendizagem das ciências na perspectiva investigativa implica em ingressar os alunos na forma científica de conhecer o mundo (DRIVER et al., 1999).

Observou-se que, mesmo tendo se revelado complexas, as atividades foram produtivas, com os alunos querendo repeti-las, fazendo perguntas e interagindo o tempo todo, mostrando-se vibrantes com o que visualizavam na lupa e no microscópio. Inferiuse que alguns estudantes conseguiram, ainda que de forma simples, identificar e representar alguns organismos que vivem no habitat aquático, atribuindo-lhes, em alguns casos, importância ecológica, como por exemplo, ao relatar o papel de plantas aquáticas, algas e peixes para alimentação de outros seres vivos, abordando ainda que superficialmente a cadeia alimentar. A aprendizagem por meio de atividades empíricas é uma necessidade para o Ensino de Ciências (SANTOS, 2005).

Para Arce, Silva e Varotto (2011), o Ensino de Ciências designa um campo de conhecimentos e um conjunto de atividades que permitem uma visão científica do mundo real, simultaneamente ao desenvolvimento de habilidades. Essa premissa pode ser corroborada, sempre que se busca verificar informações e fatos por meio de observação e investigação. Nessa perspectiva, “[...] a escola fundamental tem o dever social de colocar a criança em contato com uma forma particular de conhecimento: o conhecimento científico" (ARCE; SILVA; VAROTTO, 2011, p. 9). 
A sequência de atividades práticas foi implementada com o propósito de trabalhar a percepção dos alunos sobre os organismos que vivem na água. Nessa perspectiva, entende-se que a observação direta dos organismos se mostrou como uma estratégia de ensino relevante para o aprendizado e que deve ser considerada. Segundo Driver et al. (1999), o contato do estudante com o mundo científico poderá desenvolver o interesse do mesmo pelo campo das Ciências Naturais. Assim, estimular o interesse dos alunos envolvendo-os em atividades investigativas, contribuiu para desenvolver habilidades, especialmente no manuseio de equipamentos científicos e oportunizou, por intermédio das práticas, uma aproximação com alguns conceitos relacionados à água e à biodiversidade aquática.

\section{Considerações finais}

O estágio, por meio da prática, produz subsídios capazes de aprimorar recursos e potencialidades, envolvidos no processo de ensino e aprendizagem. A vivência da prática docente oportuniza ao professor em formação desenvolver um saber prático no cotidiano com os alunos, mediado, conforme Tardif (2010), por outros saberes pedagógicos que irão orientar suas ações na construção do conhecimento.

Para efetivar essa experiência de estágio, recorreu-se à contribuição de instrumentos como a interdisciplinaridade e a experimentação, na elaboração e concretização das aulas, de forma que, no contexto das atividades docentes exercidas, a temática da água, como também, a diversidade de vida nela contida, tivessem sua aprendizagem potencializada.

A interdisciplinaridade, através da interdependência de diferentes domínios do conhecimento, oportunizou a concretização de aulas com uma maior interface entre os conteúdos, permitindo que o tema em estudo permeasse diferentes disciplinas. A temática da água apresentou-se apropriada a uma abordagem interdisciplinar, em razão de ela oportunizar um leque amplo de possibilidades de saberes, que podem ser relacionados e contextualizados ao tema. A efetivação dessa abordagem exigiu da licencianda buscar e planejar recursos didáticos criativos e adequados que conectassem 
informações disciplinares, organizando atividades e elaborando situações, as quais permitissem envolver os estudantes com o próprio aprendizado, considerando, ainda, o contexto das aulas realizadas e as especificidades da turma. Nesse sentido, estabeleceuse um diálogo entre disciplinas variadas, tendo em vista que estas, algumas vezes, não conseguem, isoladamente, responder de forma satisfatória questões envolvidas em uma maior dificuldade.

No que tange à experimentação, é possível compreender que a utilização de atividades experimentais no Ensino de Ciências, através de propostas que instiguem a curiosidade dos estudantes, proporcionando-lhes uma aproximação com as práticas da Ciência, coadunando-as a conceitos e habilidades, podem contribuir, de forma eficaz, no processo de construção do conhecimento.

Entende-se que o percurso do estágio apontou caminhos metodológicos interessantes e produtivos, representados neste trabalho pela experimentação e interdisciplinaridade, que oportunizaram, além de atividades investigativas, uma integração professor-conteúdo-aluno, viabilizando-se, como estratégias possíveis ao desenvolvimento do processo de ensino e aprendizagem.

\section{Referências}

ARCE, Alessandra; SILVA, Debora. A. S. M. da; VAROTTO, Michele. Ensinando ciências na educação infantil. Campinas: Alínea, 2011.

BARTZIK, Franciele; ZANDER, Leisa Daniele. A importância das aulas práticas de ciências no ensino fundamental. Revista @rquivo Brasileiro de Educação, Belo Horizonte, v.4, n. 8, p. 31-38, maio/ago. 2016.

BORGES, Antônio Tarciso. Novos rumos para o laboratório escolar de ciências. Caderno Brasileiro de Ensino de Física, v. 19, n. 3, p. 291-313, 2002.

BRASIL. Ministério da Educação. Parâmetros curriculares nacionais. Brasília: Ministério da Educação, 1998.

BRASIL. Ministério da Educação. Base nacional comum curricular. Brasília: Ministério da Educação, 2017. 
CASTRO, Rafael Gil de; MOTOKANE, Marcelo Tadeu. A alfabetização científica e o ensino por investigação como pressupostos teórico-metodológicos para a elaboração de uma sequência de uma sequência didática investigativa sobre biodiversidade. In: ENCONTRO NACIONAL DE PESQUISA EM EDUCAÇÃO EM CIÊNCIAS, 11., 2017, Florianópolis. Anais [...]. Florianópolis: UFSC, 2017. p. 1-10.

CASACA, Bruno de Matos. Importância do estudo da biodiversidade: concepção de estudantes finalistas do ensino médio. In: CONGRESSO NACIONAL DE EDUCAÇÃO, 12., 2015, Curitiba. Anais [...]. Curitiba: PUCPR, 2015. p. 1-13.

CHASSOT, Attico. Alfabetização científica: questões e desafios para a educação. ljuí: Editora Unijuí, 2000.

DRIVER, Rosalind et al. Construindo conhecimento científico na sala de aula. Química Nova na Escola, São Paulo, n. 9, p. 31-40, maio 1999.

FAZENDA, Ivani. Integração e interdisciplinaridade no ensino brasileiro: efetividade ou ideologia. 6. ed. São Paulo: Edições Loyola: 1979.

FAZENDA, Ivani. A Interdisciplinaridade: um projeto em parceria. São Paulo: Loyola,1993

FAZENDA, Ivani. Interdisciplinaridade: qual o sentido? São Paulo: Paulus, 2006.

FAZENDA, Ivani. O que é Interdisciplinaridade? São Paulo: Cortez, 2008.

FOUREZ, Gerard. Approches didatiques de línterdiscipolinarité. Bruxelas: Deboeck Université, 2002.

FOUREZ, Gerard. A crise no ensino de ciências. Investigações em Ensino de Ciências, Porto Alegre v. 8, n. 2, p. 109-123, 2003.

FREIRE, Paulo. Educação "bancária" e educação libertadora. In: PATTO, Maria Helena S. (org.). Introdução à psicologia escolar. São Paulo: Casa do Psicólogo, 1997. p. 61-78.

FRIGOTTO, Gaudêncio. A interdisciplinaridade como necessidade e como problema nas ciências sociais. In: JANTSCH, Ari. Paulo.; BIANCHETTI, Lucidio. (orgs).

Interdisciplinaridade: para além da filosofia do sujeito. Petrópolis: Vozes, 1995. p.1-204.

GASPARIN, João Luis. Uma didática para a pedagogia histórico-crítica. 3. ed. Campinas: Autores Associados, 2002. 
GHEDIN Evandro; OLIVEIRA, Elisângela S.; ALMEIDA, Whasgthon. Estágio com pesquisa. São Paulo: Cortez, 2015.

GÓMEZ Al Pérez; SACRISTÁN, Gimeno. Compreender e transformar o ensino. Artmed: Porto Alegre, 2007.

GRASSI, M. T. Águas no planeta Terra. Cadernos Temáticos de Química Nova na Escola, São Paulo p. 31-40, maio 2001. Edição especial.

JAPIASSU, Hilton. Ciências: questões impertinentes. São Paulo: Ideias \& Letras, 2011.

LENOIR, Yves. Didática e Interdisciplinaridade: uma complementaridade necessária e incontornável. In: FAZENDA, Ivani (org.). Didática e Interdisciplinaridade. Campinas: Papirus, 2005. p. 1-195.

LÜCK, Heloisa. Pedagogia interdisciplinar: fundamentos teórico-metodológicos. Petrópolis: Vozes, 1994.

MOREIRA, Ana Lúcia Olivo Rosa et al. Biodiversidade na realidade escolar - Investigação da prática docente no ensino fundamental. In: ENCONTRO NACIONAL DE PESQUISA EM EDUCAÇÃO EM CIÊNCIAS, 6., 2003, Florianópolis. Anais [...]. Florianópolis: [s.n.], 2003. p. $1-9$.

MOTOKANE, Marcelo Tadeu. Sequências Didáticas Investigativas e Argumentação no Ensino de Ecologia. Educ. Ciênc., Belo Horizonte, v. 17, p.115-138, 2015. Número especial.

PIMENTA, Selma Garrido. Saberes pedagógicos e atividade docente. São Paulo: Cortez, 1999.

PIMENTA, Selma Garrido; LIMA, Maria Socorro Lucena. Estágio e docência. São Paulo: Cortez, 2005.

SANTOS, Cesar Sátiro. Ensino de ciências: abordagem histórico-crítica. Campinas: Autores Associados, 2005.

SASSERON, Lúcia Helena; CARVALHO, Ana Maria Pessoa. Alfabetização científica: uma revisão bibliográfica. Investigações em Ensino de Ciências, São Paulo: USP, v. 16, n. 1, p. 59-77, 2011.

TARDIF, Maurice. Saberes docentes e formação profissional. Petrópolis: Vozes, 2002. 
TARDIF, Maurice. Saberes docentes e formação profissional. 4. ed. Rio de Janeiro: Vozes, 2010.

THIESEN, Joarez da Silva. A Interdisciplinaridade como movimento de articulação no processo ensino-aprendizagem. PerCursos, Florianópolis, v.8, n.1, p. 87-102, jan./jun. 2008.

Recebido em: 15/04/2020 Aprovado em: 11/08/2020

Universidade do Estado de Santa Catarina - UDESC Centro de Ciências Humanas e da Educação - FAED PerCursos

Volume 21 - Número 47 - Ano 2020 revistapercursos@gmail.com 